\title{
Adsorption of Methylene Blue from Aqueous Solution by AB-8 Macroreticular Resin
}

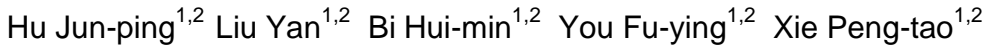 \\ ${ }^{1}$ School of Chemical and Materials of Handan College, Handan, 056005, China \\ ${ }^{2}$ Chemistry and Chemical engineering Experiment Teaching Center of Handan College, Handan
}

\begin{abstract}
Study on adsorption kinetics and thermodynamics of methylene blue by AB-8 macroreticular resin was carried out through static experiments. The results showed that the adsorption rate for the solute appear to be the first order kinetics, the intraparticle diffusion is the main rate-controlling step. In the experimental temperature, thermodynamic studies indicated that methylene blue adsorption onto resin AB-8 conforms to Langmuir and Freundlich adsorption isotherm. Methylene blue adsorption quantity respectively $30 \mathrm{mg} / \mathrm{L}, 150 \mathrm{mg} / \mathrm{L}$, and $300 \mathrm{mg} / \mathrm{L}$. The adsorption enthalpy change is $40.3 \mathrm{~kJ} / \mathrm{moL}, 39.2 \mathrm{~kJ} / \mathrm{moL}$, and $33.6 \mathrm{~kJ} / \mathrm{moL}$ respectively. The uptake of salicylic acid on AB-8 macroreticular resin is a type of physical adsorption.
\end{abstract}

\section{Introduction}

Along with the quick development of national economy, the industrial wastewater has become one of the main sources of water pollution, especially in printing and dyeing wastewater because of its deep color, chemical oxygen demand (COD), biochemical oxygen demand (BOD) value is higher, composition is complicated, wide distribution of surface [1], and is becoming a hot spot of environmental protection workers is becoming more and more attention. The common method of printing and dyeing wastewater treatment have different limitations, such as chemical precipitation treatment of printing and dyeing wastewater will produce a lot of difficult to deal with the sludge; Biological methods while running cost is low, but cannot make dye wastewater decolorizing completely, and toxic side effects on microorganisms. And adsorption method as a kind of important physical and chemical method, in dealing with the organic matter pollution including printing and dyeing wastewater has important applications in [2]

In the paper, we mainly studied the AB-8 macroreticular resin adsorption of methylene blue adsorption behavior, Discussing the different oscillation velocity and initial concentration under the condition of adsorption dynamics, and the influence of different temperature on the adsorption equilibrium, in order to AB-8 macroreticular resin adsorption of methylene blue wastewater process have a further understanding, for the resin in the methylene blue do a preliminary theoretical exploration of the application of wastewater treatment.

\section{Experimental}

\subsection{Experimental materials and equipment}

SHA-B thermostatic oscillator (Guohua enterprises); UNICAM uv-vis spectrophotometer (USA); Methylene blue (analysis of pure, Shanghai chemical plant); AB-8 macroreticular resin (Cangzhou treasure well chemical co., LTD); Milky white opaque spherical particles, particle size $0.3-1.25 \mathrm{~mm}$, average pore size $13 \sim 14 \mathrm{~nm}$, specific surface area $480 \sim 520 \mathrm{~m}^{2} / \mathrm{g}$.

\section{2 Experimental method}

\subsubsection{The pre-treatment of the resin}

Take a certain amount of AB-8 resin, $24 \mathrm{~h}$ after soaking with ethanol, with deionized water elution clean and dry.

\subsubsection{The determination of static adsorption kinetics}

AB-8 macroreticular resin was weight $150 \mathrm{mg}$ accurate in the iodine flask, dry resin added with a certain volume of deionized water swelling after 24 hours, fully filter to excess water, add a certain amount of methylene blue standard solution, under the temperature of $298 \mathrm{k}$ at 100 $\mathrm{r} / \mathrm{min}$ constant temperature oscillation, interval time determination of methylene blue solution concentration.

\subsubsection{The influence of vibration velocity and initial concentration on adsorption Formatting the title, authors and affiliations}


At the first, AB-8 macroreticular resin was weighing out $0.5 \mathrm{~g}$ after pre-treatments of drying, and dosing to several containing $100 \mathrm{ml}$ methylene blue solution grinding flat bottom flask, preparation of methylene blue solution concentration of $500 \mathrm{mg} / \mathrm{L}$, placed in a thermostatic oscillator, control temperature $28{ }^{\circ} \mathrm{C}$, the oscillation speed respectively 100,150 , and $250 \mathrm{r} / \mathrm{min}$, timing sampling analysis. oscillation velocity influence on adsorption was tested; Under the same conditions for the oscillation speed of $200 \mathrm{r} / \mathrm{min}$, initial concentration of methylene blue were $33 \mathrm{mg} / \mathrm{L}, 152 \mathrm{mg} / \mathrm{L}, 308 \mathrm{mg} / \mathrm{L}$ adsorption experiments.

\subsubsection{The influence of temperature on the adsorption equilibrium}

Dry resin Said was taking $0.5 \mathrm{~g}$, cast to join respectively containing $50 \mathrm{ml}$ methylene blue solution grinding mouth flasks, concentration of methylene blue of $25 \mathrm{mg} / \mathrm{L} 50 \mathrm{mg} / \mathrm{L}, 100 \mathrm{mg} / \mathrm{L}, 200 \mathrm{mg} / \mathrm{L}, 300 \mathrm{mg} / \mathrm{L}$, $400 \mathrm{mg} / \mathrm{L}$ and $500 \mathrm{mg} / \mathrm{L}$, respectively, at $20{ }^{\circ} \mathrm{C}$ 、 $40{ }^{\circ} \mathrm{C} 、 60{ }^{\circ} \mathrm{C}$ under three different temperature, speed of $200 \mathrm{r} / \mathrm{min}$ oscillations to adsorption equilibrium after sample analysis respectively.

\subsubsection{Analysis method}

Under $668 \mathrm{~nm}$ wavelength, concentration of methylene blue analysis using by UNICAM uv - vis spectrophotometer. Adsorption of methylene blue on the resin based on $\mathrm{qt}=(\mathrm{C} 0-\mathrm{Ct}) \mathrm{V} / \mathrm{W}, \mathrm{C} 0, \mathrm{Ct}$ of methylene blue respectively when the initial concentration and time $\mathrm{t}$ (min) methylene blue solution concentration $(\mathrm{mg} / \mathrm{L}), \mathrm{V}$ (L) for solution volume, $\mathrm{W}$ for $\mathrm{AB}-8$ macroreticular resin weight $(\mathrm{g})$.

\section{RESULTS AND DISCUSSION}

\subsection{Adsorption kinetics research}

Time, temperature, initial concentration, oscillation speed, $\mathrm{pH}$, and many other external factors influence on adsorption process to some extent[3], this article mainly discusses time, different speed of oscillation and the influence of the initial concentration of the methylene blue adsorption[4]. At the same time, using simulation level of adsorption dynamics model to fitting of adsorption process, having certain prediction for adsorption behaviour. Lagergren equation is solid-liquid adsorption system simulation analysis of one of the commonly used model[4,5,6]. Methylene blue in AB-8 macroreticular resin adsorption equation expression for formula (1)

$$
\log C_{t}=\log C_{e}+K t / 2.303
$$

In the formula, $\mathrm{K}$ is rate constant, $\min ^{-1} ; \mathrm{t}$ as time used for adsorption, min; $\mathrm{C}_{\mathrm{e}}$ for salicylic acid solution concentration at the time of adsorption equilibrium, $\mathrm{mg} / \mathrm{L} ; \mathrm{C}_{\mathrm{t}}$ was methylene blue on the $\mathrm{AB} 8$ resin adsorption quantity and balance the difference between the adsorption quantity at the $t$ time.

To $\log C t$ vs $t$ drawing, if a straight line, are proved to first order kinetics model can describe the adsorption process.

Ion exchange process generally experience three steps:

(1) ion solution by the liquid film diffusion to the resin surface;

(2) by the resin surface to the internal diffusion;

(3) ion exchange reaction active group position within the resin.

The ion exchange process by liquid film diffusion, particle diffusion and chemical reaction rate of 3 steps, The influence of the speed of the slowest step is to control the rate. Generally soon, due to chemical reaction is difficult to become a speed control steps, often using particle diffusion equation (2) to calculate.[7,8]

Particle diffusion rate formula

$$
\mathrm{q}_{\mathrm{t}}=\mathrm{K}_{\mathrm{i}} \mathrm{t}^{0.5}
$$

Adsorption rate constant $\mathrm{K}$ for $\min ^{-1} ; \mathrm{K}_{\mathrm{i}}$ for particle diffusion rate constant in $\mathrm{mg} /\left(\mathrm{g} \mathrm{min}^{0.5}\right)$; $\mathrm{T}$, min.

\subsubsection{The adsorption kinetics curve}

Adsorbent adsorption in liquid phase, is essentially the solvent and the component adsorption of the adsorbent competition, when the adsorption effect of the solvent can be ignored, the adsorption system according to the single component adsorption to deal with.Adsorption curve, namely static exchange kinetics curve, characterization of the adsorbent on the adsorption properties of adsorption process of change over time. As shown in figure 1 .

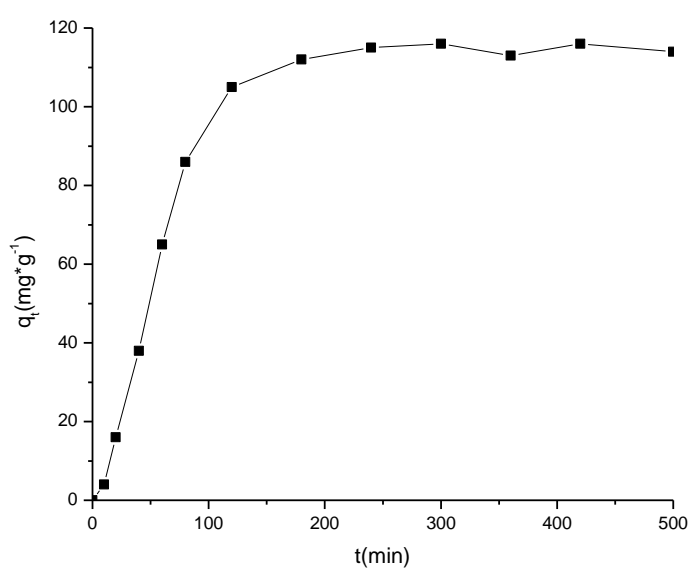

Fig.1 Adsorption kinetics curve of $\mathrm{AB}-8$ resin toward methylene blue

By the figure 1 can be seen AB- 8 resin adsorption of methylene blue as time increases, basic equilibrium adsorption at $180 \mathrm{~min}$. 


\subsubsection{The influence of oscillation speed of adsorption}

The figure 2 , table 1 shows that $\log C t$ on $t$ show a good linear relationship $\left(\mathrm{R}^{2}\right.$ more than 0.98), showed that methylene blue on the AB-8 resin adsorption for the first order kinetics. According to Mackay [9], when the type (1) in the $\mathrm{q}_{\mathrm{t}}$ with $\mathrm{t}^{0.5}$ show good linear relationship and through the origin, the material within the particle diffusion process as adsorption rate control steps.

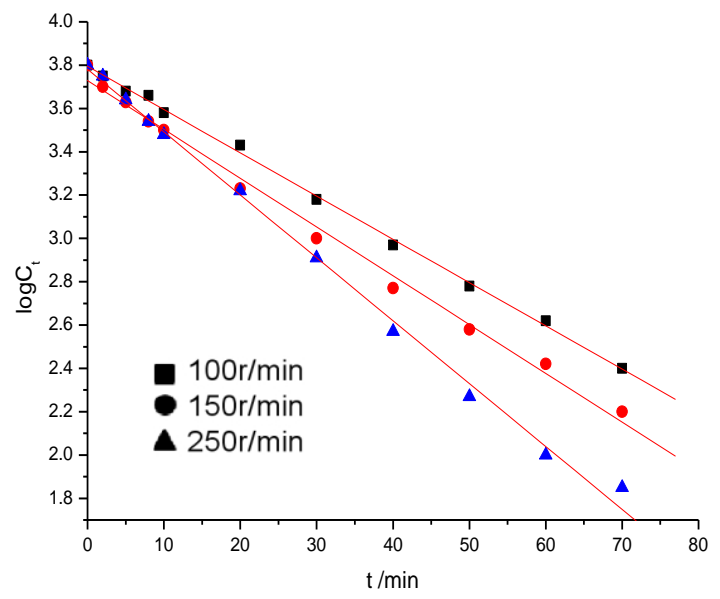

Fig.2 Effect of agitation rate on adsorption rate

Table 1 Adsorptions rates and intrapartical diffusion constants under different agitate speed and initial concentration

\begin{tabular}{|c|c|c|c|c|}
\hline & $\begin{array}{c}\mathrm{K},\left(* 10^{-}\right. \\
\left.{ }^{2}\right) \min ^{-1}\end{array}$ & $\overline{\mathbf{R}^{2}}$ & $\begin{array}{c}\mathbf{K}_{\mathrm{i}}, \mathrm{mg} /(\mathrm{g} \\
\mathrm{min})^{0.5}\end{array}$ & $\overline{\mathbf{R}^{2}}$ \\
\hline $\begin{array}{c}\text { Agitate } \\
\text { speed,r/min } \\
100\end{array}$ & 0.83 & 0.968 & 12.88 & 0.985 \\
\hline 150 & 1.38 & 0.985 & 13.54 & 0.995 \\
\hline 250 & 1.52 & 0.987 & 13.67 & 0.984 \\
\hline \multicolumn{5}{|l|}{$\overline{\mathrm{C}_{0}, \mathrm{mg} / \mathrm{L}}$} \\
\hline 33 & 0.21 & 0.978 & 1.32 & 0.998 \\
\hline 152 & 0.11 & 0.972 & 3.53 & 0.993 \\
\hline 308 & 0.09 & 0.968 & 8.88 & 0.986 \\
\hline
\end{tabular}

The figure 3 , table 1 shows that under the condition of three different oscillation of $\mathrm{qt}$ and $\mathrm{t}_{0.5}$ show good linear relationship, but as a result of these lines are not through the origin, that methylene blue adsorption on $\mathrm{AB}-8$ resin particle diffusion process inside is not the only control step, the adsorption rate affected by particle diffusion process of adsorption of colleagues.

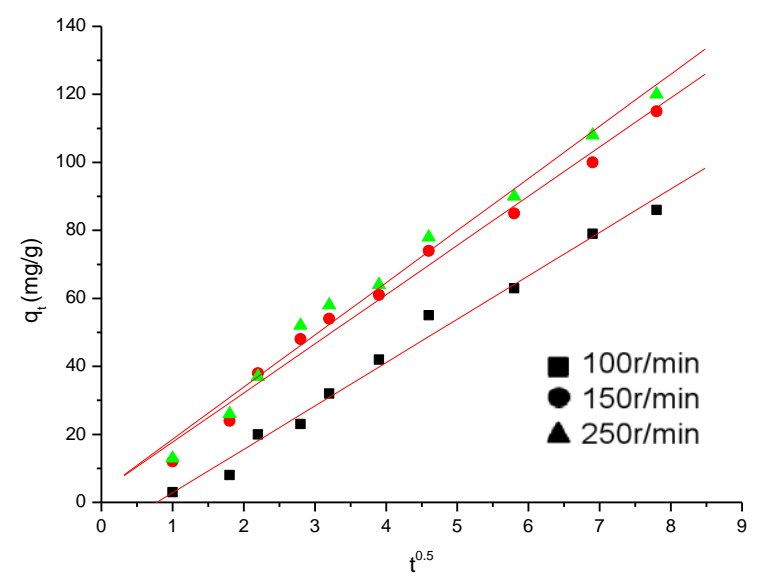

Fig.3 Effect of agitation rate on intrapartical

\subsubsection{The influence of initial concentration on adsorption}

From table 1 and figure 4, figure 5 shows that changes in the concentration range of methylene blue on the AB-8 resin adsorption rate in line with the first order kinetics equation, in different initial concentration, despite the particle diffusion process has great influence to the adsorption, but still is not the only control the adsorption rate of step.

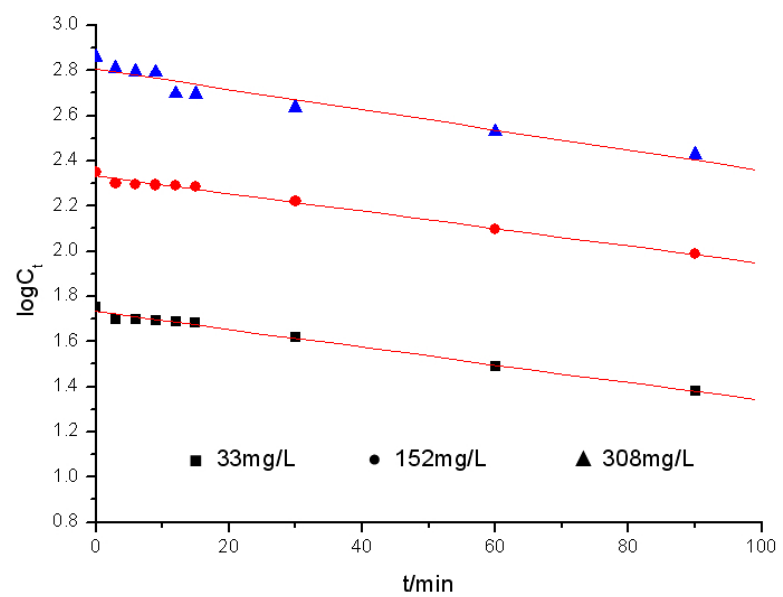

Fig.4 Effect of initial concentration on adsorption rate

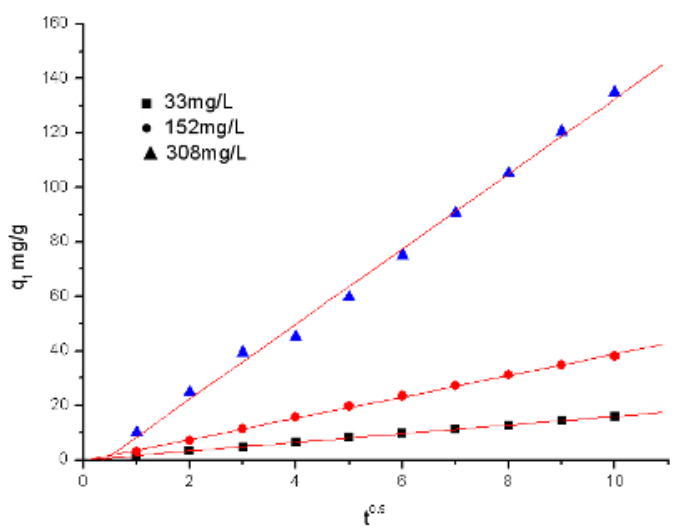

Fig.5 Effect of initial concentration on intrapartical diffusion 


\subsection{The influence of temperature on the adsorption equilibrium}

Figure 6 shows that methylene blue on the AB- 8 resin adsorption quantity increases with the increase of equilibrium concentration [10], however, as the adsorption and the rise of temperature, by Langmuir and Freundilich isothermal equation of figure 5 data fitting results are shown in table 2 , the results show that the Langmuir and Freundilich isothermal equation can well describe the $\mathrm{AB}-8$ adsorption of methylene blue

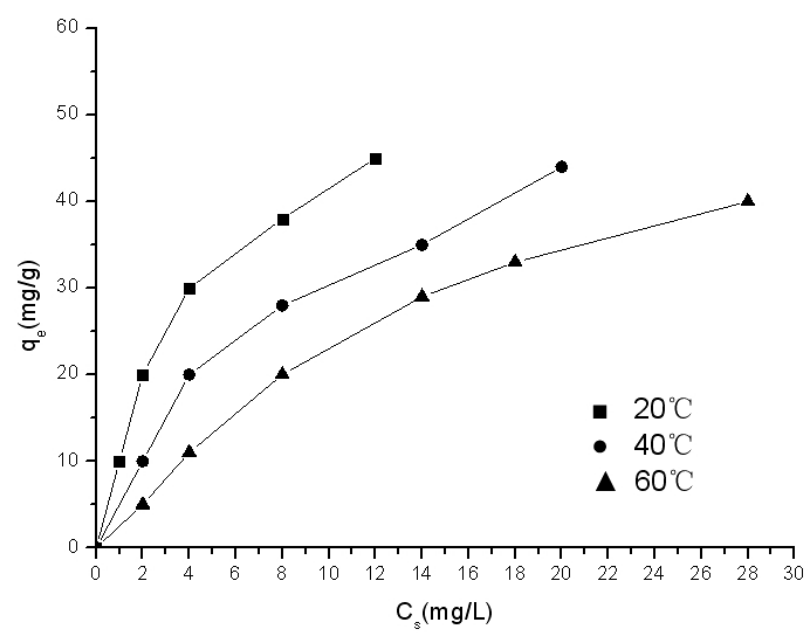

Fig.6 Effect of temperature on adsorption equilibrium

Table 2 Parameters for Langmuir and Freundlich equitions

\begin{tabular}{ccccccc}
\hline $\mathbf{T},{ }^{\circ} \mathbf{C}$ & $\mathbf{X m}$ & $\mathbf{a}_{\mathbf{L}}$ & $\mathbf{R}^{\mathbf{2}}$ & $\mathbf{K}_{\mathbf{F}}$ & $\mathbf{b}$ & $\mathbf{R}^{\mathbf{2}}$ \\
\hline 20 & 85.2 & 0.168 & 0.995 & 9.18 & 0.7755 & 0.987 \\
40 & 52.3 & 0.198 & 0.996 & 6.58 & 0.7152 & 0.992 \\
60 & 49.2 & 0.121 & 0.981 & 3.69 & 0.8205 & 0.991 \\
\hline
\end{tabular}

\subsection{The adsorption enthalpy change of methylene blue on the AB-8 resin}

In adsorption, the enthalpy change can be gat by Van 't Hoff equation. Van' t Hoff equation is $\ln \left(1 / \mathrm{C}_{1}\right)=\ln \mathrm{K}+$ (- $\Delta \mathrm{H} / \mathrm{RT}) .-\Delta \mathrm{H}^{0}$ is adsorption enthalpy $\mathrm{kJ} / \mathrm{moL} ; \mathrm{T}$ as absolute temperature, $\mathrm{K}$; For the ideal gas constant $\mathrm{R}$ is $8.314 \mathrm{~kJ} / \mathrm{moL}, \mathrm{K}) ; \mathrm{C}_{1} \quad\left(\mathrm{C}_{1}=\mathrm{Ce}\right.$, methylene blue molecular weight 319.86 and Ce values calculated by the Langmuir equation) for the adsorption of methylene blue solution at $\mathrm{q}$ equilibrium concentration tendency/ $\mathrm{mmoL} / \mathrm{L}$.

Methylene blue adsorption quantity respectively $30 \mathrm{mg} / \mathrm{L}$, $150 \mathrm{mg} / \mathrm{L}$, and $300 \mathrm{mg} / \mathrm{L}$. The adsorption enthalpy change is $40.3 \mathrm{~kJ} / \mathrm{moL}, 39.2 \mathrm{~kJ} / \mathrm{moL}$, and $33.6 \mathrm{~kJ} / \mathrm{moL}$ respectively. Adsorption enthalpy change $\Delta \mathrm{H}$ negative, indicating that the adsorption process is exothermic process, and the smaller of absolute value of enthalpy change (less than $42 \mathrm{~kJ} / \mathrm{moL}$ ), shows that the adsorption process for the obvious physical adsorption properties. Adsorption enthalpy decreases with the increase of the adsorption quantity, may be due to the inhomogeneity of the surface of the resin adsorption mass adsorption was first to energy of position.

\section{CONCLUSION}

(1) Kinetics study showed that AB-8 resin adsorption of methylene blue good pseudo-first-order kinetics equation ( $R 2>0.99$ ) 。

(2)AB-8 resin adsorption of methylene blue speed steps for particle diffusion process.

(3)Within the scope of the study, methylene blue by $A B-8$ resin on the equilibrium adsorption data could very well in Langmuir and Freundilich isothermal adsorption equation fitting, adsorption quantity increases with the increase of concentration of methylene blue.

(4)Thermodynamic study, Adsorption enthalpy turned negative, indicating that the adsorption reaction is exothermic physical adsorption process, easier for adsorption and adsorption performance is good, the results show that $A B-8$ macroreticular resin can be used for methylene blue wastewater pollution control and resource recycling.

\section{References}

1. Bhattacharyya K G, Gupta S.Industrial and Engineering Chemistry Research

2. Structure and Fluorescence Emission of HeteroNuclear Complexes of Europium-Lanthanum Nitrates with N,N'-Substituted Adipamide - 2002

3. Ho Y S, Mckay G. A kinetic study of dye sorption by biosorbent waste product pith [J]. Resources Conservation and Recycling, 1999 25:171-193

4. The Diels-Alder Reaction on Endohedral Y3N@C78: The Importance of the Fullerene Strain Energy 2009

5. Qin Li-hong, Zhang Feng-bao,Zhang Guo-liang. Kinetics and mechanism of the sorption of NTS macroreticular adsorption resin $[\mathrm{J}]$. Chemical Industry and Engineering, 2007,24(3):245-248

6. E Metwally. Kinetic studies for sorption of some metal ions from aqueous acid solutions onto TDA impregnated resin[J]. Journal of Radioanalytical and Nuclear Chemistry,2006,270(3) :559-566

7. Guo Zhou, Yuan Yue. Kinetics and themodynamics of adsorption of phenol onto mesoporous carbon CMK-3[J]. Chemical Journal of Chinese University, 2007, 28(2) :289-292

8. Dinesh Mohan, Kunwar $P$ Singh. Single-and multicomponent adsorption of cadmium and zinc using activated carbon derived from bagasse - an agricultural waste[J]. Water Research, 2002,9(36) : 2304-2318

9. Mamdouh Mahmoud Nassar. Intraparticle diffusion of basic red and basic yellow dyes on palm fruit bunch [J]. Wat Sci Tech, 1999, 40(7):133-139

10. Enhanced photocatalytic activity of electrosynthesised tungsten trioxide-titanium dioxide bi-layer coatings under ultraviolet and visible light illumination - 2007 